18

\title{
Фотостабильность и фотоиндуцированные процессы в квантовых точках CulnS $/$ ZnS и их гибридных структурах с многослойными нанолентами графена
}

\author{
(C) И.А. Резник ${ }^{1}$, Д.А. Куршанов ${ }^{1}$, А.Ю. Дубовик ${ }^{1}$, М.А. Баранов ${ }^{1}$, \\ С.А. Мошкалев ${ }^{2}$, А.О. Орлова ${ }^{1}$, А.В. Баранов ${ }^{1}$ \\ ${ }^{1}$ Университет ИТМО, \\ 197101 Санкт-Петербург, Россия \\ ${ }^{2}$ State University of Campinas (Unicamp), \\ SP 13083-970 Campinas, Brazil \\ e-mail: ivanreznik1993@mail.ru
}

Поступила в редакцию 28.06.2020 г.

В окончательной редакции 28.06.2020 г.

Принята к публикации 16.07.2020 г.

Исследованы фотостабильность люминесцентных свойств $\mathrm{CuInS}_{2} / \mathrm{ZnS}$ квантовых точек (CIS/ZnS KT) в виде монослоя на диэлектрической подложке и в составе гибридной структуры с многослойными нанолентами графена (МНГ). Анализ кинетики люминесценции КТ выявил наличие трех основных компонент затухания люминесценции, характеризующихся временами порядка 20, 100 и $300 \mathrm{~ns}$. Показано, что эффективность взаимодействия CIS/ZnS КТ и МНГ имеет аналогичную CdSe КТ зависимость от количества монослоев графена. Произведена оценка фотостабильности CIS/ZnS KT на диэлектрической подложке и в составе структур с МНГ, позволившая оценить скорости переноса энергии/заряда от КТ к МНГ как $10^{6}-10^{7} \mathrm{~s}^{-1}$.

Ключевые слова: квантовые точки $\mathrm{CuInS}_{2} / \mathrm{ZnS}$, многослойные графеновые наноленты, дефектная люминесценция, перенос энергии/заряда, фотоиндуцированные процессы.

DOI: $10.21883 /$ OS.2020.11.50183.198-20

\section{1. Введение}

Квантовые точки на основе тройных соединений элементов I-III-VI групп типа $\mathrm{AgInS}_{2}$ (AIS) и $\mathrm{CuInS}_{2}$ (CIS), а также КТ с оболочкой $\mathrm{ZnS}-\mathrm{AIS} / \mathrm{ZnS}$ и $\mathrm{CIS} / \mathrm{ZnS}$ интенсивно исследуются как нетоксичная альтернатива КТ на основе селенида кадмия и теллурида кадмия для применения в фотовольтаике и биомедицине [1-4].

Первые работы, касающиеся синтеза данных КТ, появились около десяти лет назад [5]. Соединение CIS известно как прямой полупроводник с шириной запрещенной зоны $1.5 \mathrm{eV}(\sim 830 \mathrm{~nm})$. В КТ из-за квантоворазмерного эффекта ширина запрещенной зоны зависит от ее размера, а также от элементного состава КТ и лигандов на ее поверхности $[5,6]$. Поэтому как длинноволновая граница поглощения, так и пик люминесценции CIS KT могут быть изменены в диапазоне от видимого до ближнего ИК диапазона [7,8]. Для повышения стабильности оптических параметров CIS KT и увеличения квантового выхода люминесценции нанокристаллы CIS обычно покрываются оболочкой $\mathrm{ZnS}$ [9]. KT CIS/ZnS наряду с AIS/ZnS KT перспективно использовать в биомедицине в качестве доноров при переносе энергии фотовозбуждения к люминесцентным маркерам или в качестве самих люминесцентных маркеров $[10,11]$. Рассматриваются возможности их использования в качестве люминофора в новых поколениях безкадмиевых светодиодов на основе КТ [12,13]. В обоих случаях крайне необходима информация о фотостабильности квантовых точек CIS/ZnS в составе гибридных структур с диэлектрическими, например стекло или полимер, и проводящими, например графен, углеродные нанотрубки, материалами, а также о наличии каналов излучательной и безызлучательной дезактивации энергии фотовозбуждения в CIS/ZnS KT. Получение такой информации является крайне важным шагом для реализации эффективных сенсоров для биомедицинских приложений и фотовольтаических (детекторы и эмиттеры) устройств для нанофотоники с использованием КТ данного типа. Известно, что люминесцентные свойства CIS KT напрямую связаны с наличием дефектов, в том числе и фотоиндуцированных, кристаллической решетки внутри и на поверхности ядра КТ [14]. Однако на сегодняшний день не опубликовано работ, посвященных детальному исследованию фотостабильности CIS/ZnS KT.

В настоящей работе исследованы фотостабильность и фотоиндуцированные процессы в КТ CIS/ZnS, pacположенных в виде монослоя на стеклянной подложке и в составе гибридных структур с многослойными нанолентами графена. Проведен анализ кинетики люминесценции CIS/ZnS KТ для излучательных переходов с характерными временами порядка 20, 100 и 300 ns. 


\section{2. Материалы и методы}

В качестве растворителей для коллоидных КТ в работе были использованы метанол и хлороформ фирмы „Вектон“ (Россия). Графеновые наноленты растворялись в метил-2-пирролидоне (NMP) фирмы „Компонентреактив“ (Россия). Все растворители использовались без предварительной отчистки.

В качестве коллоидных КТ использованы гидрофобные полупроводниковые коллоидные КТ CIS/ZnS c полосой люминесценции на $610 \mathrm{~nm}$, синтезированные методом горячей инжекции [15] и стабилизированные молекулами додекантиола. В качестве компонента гибридных структур, обеспечивающего высокую мобильность носителей зарядов, использовались многослойные графеновые наноленты (МНГ), характеризующиеся латеральными размерами порядка $20-50 \mu \mathrm{m}$, шириной $1-5 \mu \mathrm{m}$ и толщиной $5-20 \mathrm{~nm}$ производства Nacional de Grafite (Бразилия).

Регистрация спектров поглощения и люминесценции коллоидного раствора КТ проводилась на спектрофотометре Shimadzu UV-Probe 3600 и спектрофлуориметре Cary Eclipse (Varian) соответственно. Кинетика люминесценции КТ в виде слоев на диэлектрической подложке и в составе гибридных структур с МНГ анализировалась с использованием люминесцентного микроскопа MicroTime 100 (PicoQuant).

Морфология слоев КТ и гибридных структур на их основе была исследована с помощью электронного сканирующего микроскопа MERLIN (Zeiss) и с помощью конфокального люминесцентного микроскопа LSM710 (Zeiss) в режиме проходящего света и в режиме регистрации люминесценции.

Экспериментальные кривые затухания люминесценции КТ были аппроксимированы мультиэкспоненциальной функцией:

$$
y=y_{0}+\sum_{i} A_{i} \exp \left(\frac{x-x_{0}}{\tau_{i}}\right),
$$

где $A_{i}-$ амплитуда, $\tau_{i}-$ характерное время затухания $i$-й компоненты люминесценции.

Перед формированием слоев КТ в коллоидном растворе были отмыты от избытка молекул стабилизатора с помощью процедуры осаждения КТ. К $100 \mu 1$ раствора КТ в хлороформе добавлялись такие же объемы метанола и ацетона, после чего смесь интенсивно перемешивалась. Затем КТ, выпавшие из раствора, были осаждены при помощи центрифугирования в течение $5 \mathrm{~min}$ на скорости $10000 \mathrm{rpm}$. Четырехкратное повторение данной процедуры позволило получить КТ с минимальной поверхностной концентрацией молекул стабилизатора и добиться минимального расстояния между КТ в формируемых слоях.

Слои и гибридные структуры формировались путем послойного нанесения МНГ и КТ методом Ленгмюра-Блоджетт [16] с помощью установки $\mathrm{KN}$
2002 (KSV NIMA) на стеклянные подложки. Формирование и перенос слоев КТ происходили на поверхности деионизированной воды с удельным сопротивлением $\sim 18 \mathrm{M} \Omega / \mathrm{cm}$. Перед формированием слоя НК поверхность воды очищалась от посторонних частиц с помощью воздушного насоса до момента, когда сила поверхностного натяжения пленки воды опускалась ниже $0.01 \mathrm{mN} / \mathrm{cm}$, что соответствует чистой поверхности воды по спецификациям прибора. Затем на поверхность воды выкапывался раствор вещества, после чего установку оставляли на $30 \mathrm{~min}$ для того, чтобы молекулы растворителя испарились с поверхности воды, а частицы слоя пришли в равновесное состояние. Формирование и перенос слоя КТ производилось при достижении силы поверхностного натяжения $18 \mathrm{mN} / \mathrm{cm}$. Слои МНГ были перенесены на подложку при силе поверхностного натяжения $45 \mathrm{mN} / \mathrm{cm}$.

Для исследования фотоиндуцированных изменений спектрально-кинетических параметров КТ их слой подвергался экспонированию в пятне фокусировки диаметром $\sim 50 \mu \mathrm{m}$ излучения входящего в комплект люминесцентного микроскопа MicroTime 100 (PicoQuant) полупроводникового лазера с длиной волны $409 \mathrm{~nm}$ и средней мощностью $1 \mu \mathrm{W}$. Такая конфигурация предоставляла возможность периодической регистрации кинетики затухания люминесценции КТ из выбранной области образца прямо во время экспонирования. Время регистрации кинетики $(5 \mathrm{~s})$ было существенно короче времен экспонирования (60s).

\section{3. Результаты и обсуждение}

\section{1. Характеризация CIS/ZnS KT и гибридных структур MHГ/CIS/ZnS KT}

Изотермы формирования пленок МНГ и КТ CIS/ZnS методом Ленгмюра-Блоджетт приведены на рис. 1. Как видно из рис. 1, изотерма формирования пленки КТ $\mathrm{CIS} / \mathrm{ZnS}$ постепенно выходит на плато при уменьшении площади пленки Л-Б, что указывает на формирование плотноупакованного монослоя КТ при поверхностном натяжении пленки $18 \mathrm{mN} / \mathrm{m}$ [17]. Полученный монослой затем был перенесен на диэлектрическую подложку с МНГ.

Как видно из рис. 2 , спектр люминесценции (здесь и далее PL - photoluminescence) раствора CIS/ZnS KT в толуоле имеет широкую полосу с максимумом на длине волны $610 \mathrm{~nm}$ и стоксовым сдвигом относительно экситонной полосы поглощения порядка $\sim 100 \mathrm{~nm}$. Достаточно большая ширина полосы люминесценции КТ $($ FWHM $\sim 106 \mathrm{~nm})$ была объяснена наличием энергетических состояний „собственных“ дефектов кристаллической структуры CIS KT и поверхностных ловушечных состояний („trap states“), люминесцентные переходы из которых приводят к уширению полосы люминесценции KT [18]. 


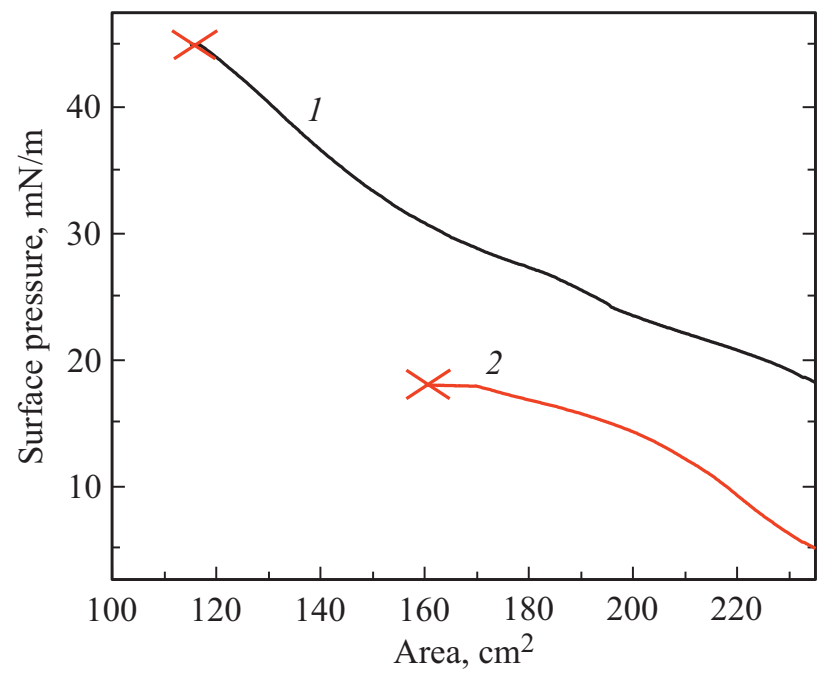

Рис. 1. Изотермы формирования пленок МНГ (1) и $\mathrm{CIS} / \mathrm{ZnS}$ (2) методом Ленгмюра-Блоджетт. Крестом обозначена сила поверхностного натяжения вовремя переноса пленки на подложку.

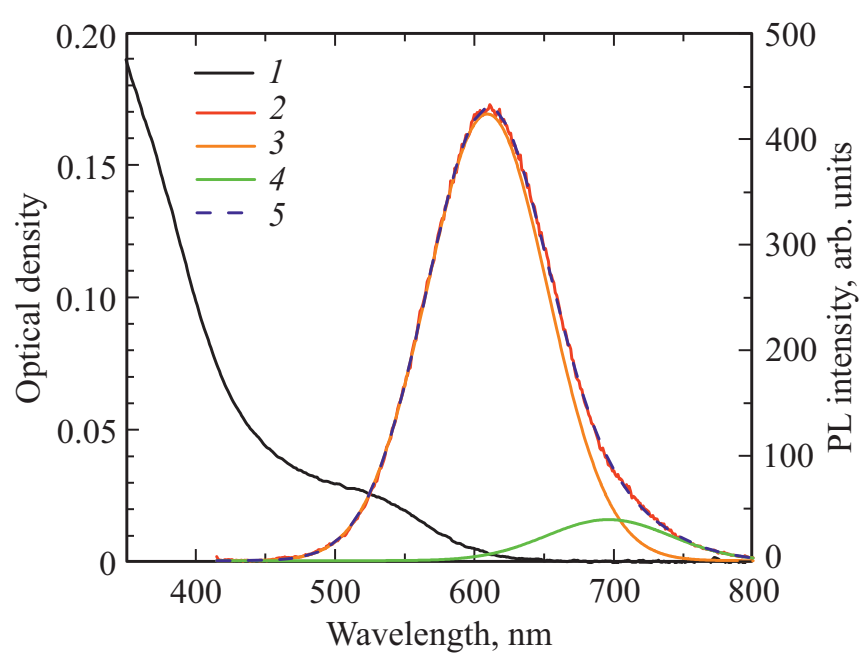

Рис. 2. Спектры поглощения (1) и люминесценции (2) $\mathrm{CIS} / \mathrm{ZnS}$ КТ в толуоле. Показано разложение спектра люминесценции (2) на две гауссовы полосы с максимумами на $\sim 610 \mathrm{~nm}(3)$ и $\sim 700 \mathrm{~nm}(4)$, а также сумма этих полос (5).

Наличие в экспериментальных спектрах (рис. 2) плеча на длинноволновом крыле полосы люминесценции может быть вызвано наличием еще одного электронного перехода, энергия которого примерно соответствует оптическому переходу на $700 \mathrm{~nm}$. Действительно, согласно литературным данным, более длинноволновая полоса может возникать в результате излучательного перехода между глубокими дефектными состояниями атомов индия и меди.

На рис. 3 представлены СЭМ-изображения слоя из МНГ (рис. 3,a), участок МНГ со слоем КТ на его поверхности (рис. $3, b$, слева) и монослоя КТ CIS/ZnS на поверхности кремниевой подложки (рис. $3, b$, справа).

Как видно из рис. $3, a$, пленка составлена из многослойных нанолент графена, расположенных на малом расстоянии друг от друга и характеризующихся сильным разбросом по линейным размерам. На рис. $3, b$ слева приведено увеличенное изображение участка одного МНГ с монослоем KT CIS/ZnS, нанесенным на его поверхность методом Ленгмюра-Блоджетт. Видно, что в слое КТ имеются разрывы, вызванные, скорее всего, присутствием при формировании слоя КТ молекул стабилизатора додекантиола. Однако малый размер этих разрывов и их незначительное количество позволяют считать пленку CIS/ZnS KT достаточно однородной.

Более детальное исследование морфологии и фотофизических свойств гибридных структур МНГ/CIS/ZnS проводилось при помощи сканирующей люминесцентной микроскопии. На рис. 4 приведены люминесцентные изображения образца, полученного последовательным нанесением методом Ленгмюра-Блоджетт на предметное стекло микроскопа слоя МНГ и слоя CIS/ZnS КT. В результате был сформирован образец, в котором области монослоя КТ присутствуют как на поверхности МНГ, так и на чистой поверхности стекла. Изображение участка образца в проходящем свете и его люминесцентное изображение были получены с использованием конфокального сканирующего люминесцентного микроскопа LSM701. Красный люминесцентный фон на рис. $4, b$ соответствует люминесценции CIS/ZnS KT на поверхности предметного стекла, в то время как более темные области соответствуют люминесценции CIS/ZnS КТ в составе гибридных структур МHГ/CIS/ZnS, в значительной степени потушенной из-за переноса энергии/заряда от КТ к МНГ.

Сравнительный анализ изображения, полученного в канале пропускания микроскопа (рис. $4, a$ ), и люминесцентного изображения (рис. $4, b$ ) демонстрирует отсутствие заметных разрывов микронного масштаба в слое CIS/ZnS КТ на поверхности МНГ.

Известно, что один монослой графена поглощает $\sim 2.3 \%$ света в видимом диапазоне [19]. Это позволяет, оценив степень ослабления света, прошедшего через МНГ, оценить количество слоев в отдельном МНГ, варьирующееся в пределах 10-30. Анализ степени тушения люминесценции КТ в области гибридных структур с МНГ различной толщины (участки образца, где оценивалась степень тушения люминесценции, показаны на рис. $4, b$ разноцветными кружками), позволил выявить зависимость интенсивности люминесценции CIS/ZnS КТ от количества монослоев графена, представленную на рис. 5.

Согласно опубликованным работам [20], в результате переноса энергии/заряда от КТ к графену уменьшение интенсивности люминесценции широко используемых $\mathrm{CdSe}$ KT, находящихся в непосредственном контакте с КТ, характеризуется экспоненциальной зависимостью от количества монослоев графена. Данные, представленные 
$a$
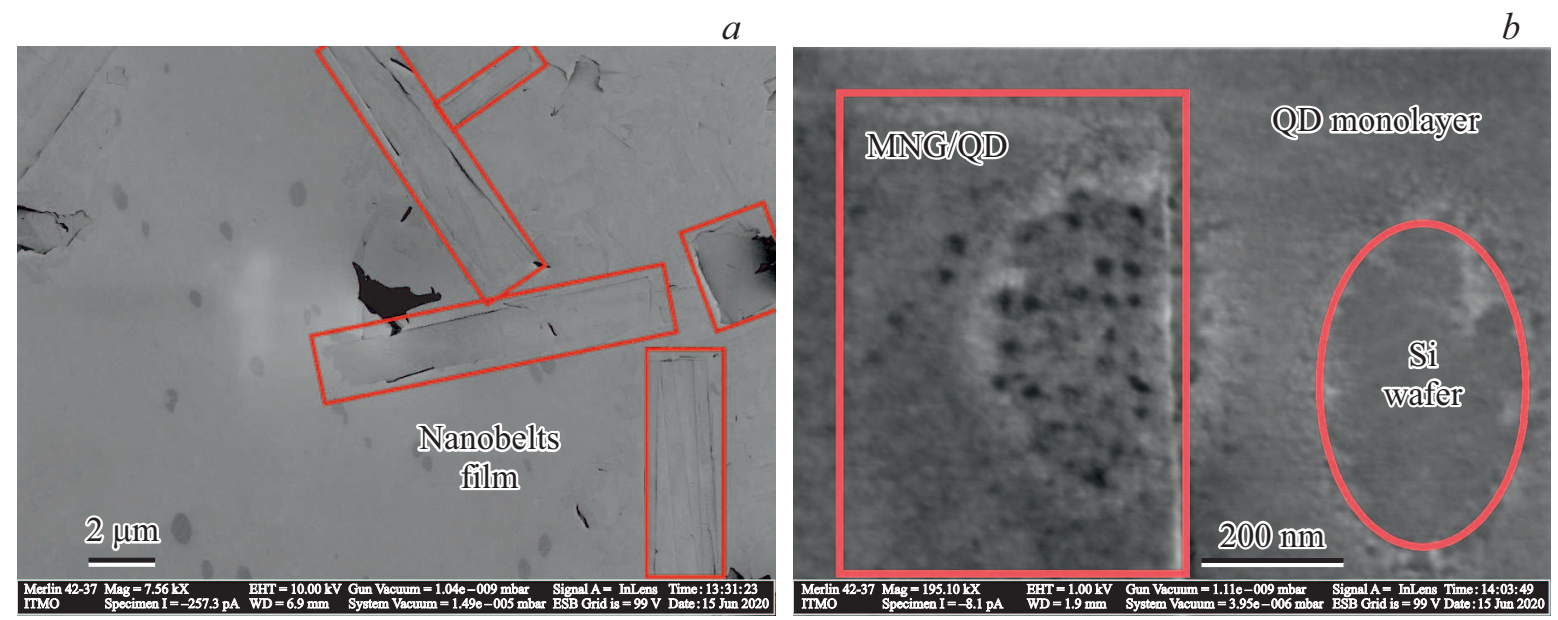

Рис. 3. Изображения со сканирующего электронного микроскопа: (a) пленка МНГ, масштабная линейка $2 \mu \mathrm{m} ;(b)$ слева (прямоугольник): участок МНГ со слоем КТ на поверхности; справа (овал): монослой KT CIS/ZnS на поверхности кремниевой подложки, масштабная линейка $200 \mathrm{~nm}$.

$a$

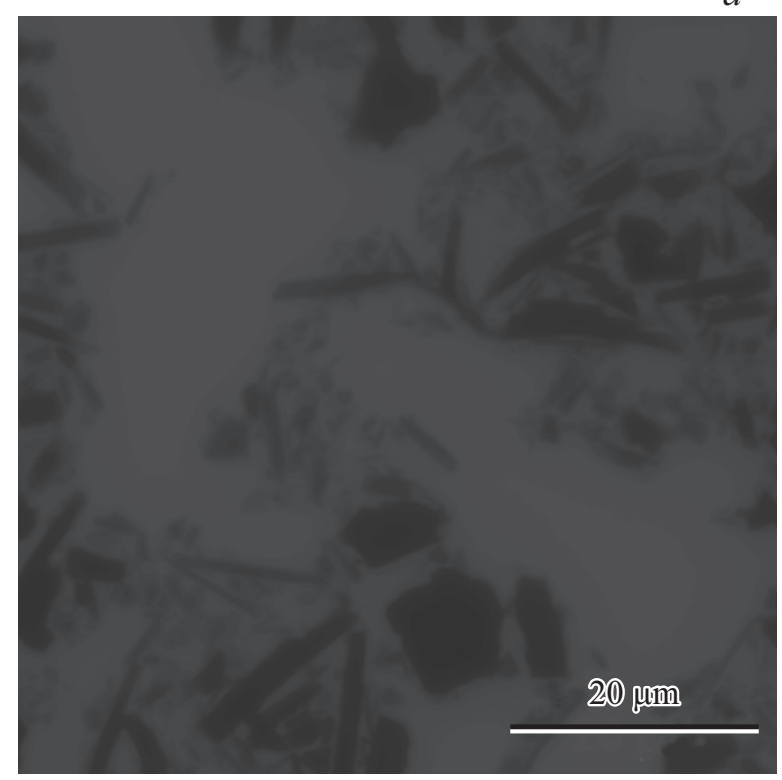

$b$

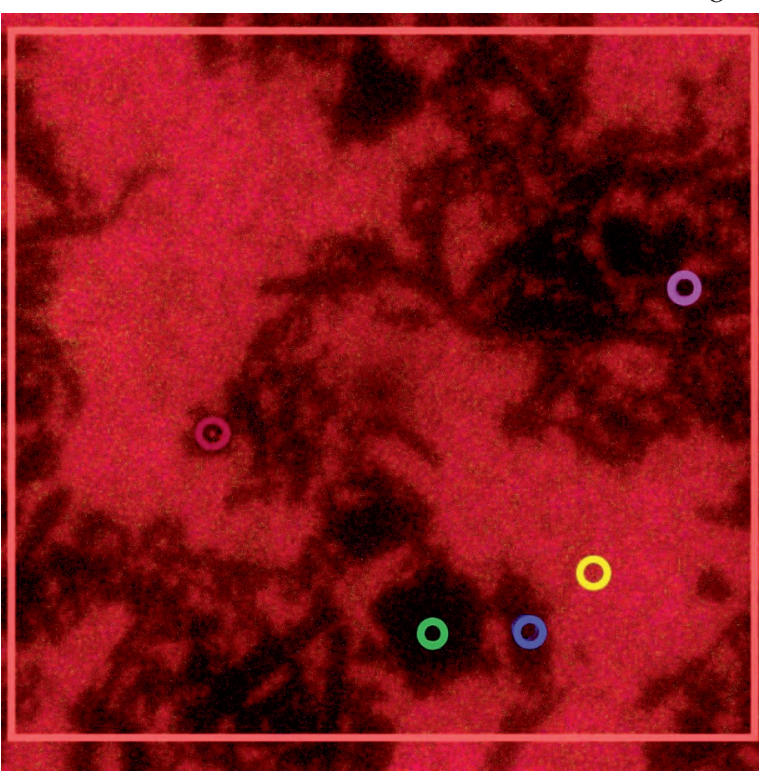

Pис. 4. (a) Изображение пленок гибридных структур MHГ/CIS/ZnS KТ на стеклянной подложке в проходящем свете. (b) Люминесцентные изображение пленок гибридных структур MHГ/CIS/ZnS KT при возбуждении излучением $405 \mathrm{~nm}$. Разноцветные кружочки показывают участки образца без МНГ и с МНГ разной толщины, для которых была оценена интенсивность люминесценции КТ. Изображения $(a)$ и $(b)$ сняты с одной и той же области с одинаковым пространственным разрешением. Показана масштабная линейка $20 \mu \mathrm{m}$.

на рис. 5, показывают, что CIS/ZnS KT, так же как и $\mathrm{CdSe} / \mathrm{ZnS}$ KT, характеризуются экспоненциальной зависимостью эффективности переноса энергии/заряда от КТ к графену от количества монослоев графена [21].

\section{2. Люминесцентные свойства CIS/ZnS KT и гибридных структур MHГ/ CIS/ZnS KT}

Основной акцент при исследовании фотостабильности и фотоиндуцированных изменений люминесцентных свойств CIS/ZnS KТ и их гибридных структур с МНГ был сделан на анализе кинетики люминесценции КТ. Это связано с тем, что в случае монослоев или образцов сверхтонких пленок, характеризующихся низкой оптической плотностью и малыми латеральными размерами (порядка нескольких десятков микрометров), регистрация стационарных спектров электронного поглощения и люминесценции сопряжена с техническими и методологическими трудностями, что не позволяет корректно (с необходимой точностью) определять количества анализируемых поглощающих или люминесцирующих 


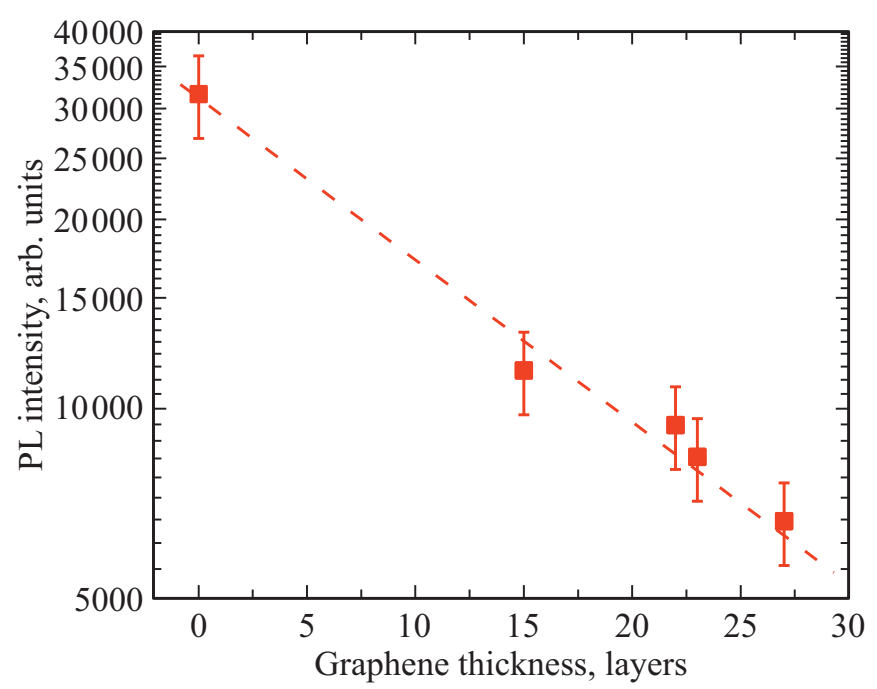

Рис. 5. Зависимость интенсивности люминесценции $\mathrm{CIS} / \mathrm{ZnS}$ КТ от количества монослоев графена в МНГ.

центров. На рис. 6 приведены кривые затухания люминесценции КТ на диэлектрической подложке и в составе гибридных структур с МНГ, зарегистрированные при широкополосном детектировании полосы люминесценции.

Кривые затухания люминесценции КТ, приведенные на рис. 6, показывают, что затухание люминесценции CIS/ZnS KT в составе гибридных структур (кривая 2) характеризуется существенно меньшими временами, чем в случае CIS/ZnS KT, на диэлектрической подложке (кривая 1). Этот факт, а также существенное уменьшение интенсивности, показанное в табл. 1, свидетельствует о тушении люминесценции КТ и наличии эффективного канала переноса энергии/заряда от КТ к МНГ. Аппроксимация экспериментальных кривых, приведенных на рис. 6, мультиэкспоненциальной функцией (1) позволила выделить 3 основные компоненты люминесценции, характеризующиеся временами $\tau_{1} \sim 20 \mathrm{~ns}, \tau_{2} \sim 100 \mathrm{~ns}$ и $\tau_{3} \sim 300$ ns. В табл. 1 приведены параметры аппроксимации для CIS/ZnS KT на диэлектрической подложке и в составе гибридных структур с МНГ.

Согласно интерпретации [15], компонента с коротким временем затухания $\left(\tau_{1} \sim 20 \mathrm{~ns}\right)$ соответствует дефектной люминесценции - дезактивацией энергии на поверхностных ловушечных состояниях („surface trap states“). Компонента люминесценции с временем затухания $\tau_{2} \sim 100 \mathrm{~ns}$ соответствует излучательному переходу между уровнем зоны проводимости и внутризонными уровнями дефектных состояний атомов меди и индия. Компонента с длительным временем затухания $\left(\tau_{3} \sim 300 \mathrm{~ns}\right)$ объясняется рекомбинацией донорноакцепторной пары между глубоким дефектным состоянием атомов меди и индия. На рис. 7 приведена энергетическая диаграмма распределения излучательных состояний в CIS/ZnS KT.
Стоит отметить, что первые две компоненты определяются двумя близко расположенными по энергии люминесцентными переходами. Это объясняет наличие только двух разрешенных между собой полос в спектре люминесценции (рис. 2).

Данные, представленные в табл. 1, демонстрируют, что при переходе от CIS/ZnS KT, расположенных на диэлектрической подложке, к гибридным структурам с МНГ наблюдается уменьшение амплитуды сигнала в 5-20 раз в зависимости от рассматриваемой фракции. Это подтверждает наличие тушения люминесценции КТ, находящихся в составе гибридных структур с МНГ, из-за наличия эффективного канала переноса энергии/заряда от CIS/ZnS KT к МНГ. При этом наблюдается перераспределение вклада люминесценции каждой компоненты при переходе к гибридным структурам МНГ/КТ. Это свидетельствует о разной эффективности тушения люминесценции излучательных переходов в результате взаимодействия КТ с МНГ в гибридных структурах.

\section{3. Исследование фотостабильности в CIS/ZnS KT и гибридных структур $\mathrm{MH} \Gamma / \mathrm{CIS} / \mathrm{ZnS} \mathrm{KT}$}

Известна лишь одна работа, где сообщается о том, что КТ тройного состава, включая CIS и CIS/ZnS KT, обладают невысокой фотостабильностью, вероятно, связанной с быстрой деградацией поверхности под действием внешнего облучения [22]. Проверка этого факта очень важна, особенно в свете предполагаемого использования таких КТ в качестве доноров энергии для биомедицинской сенсорики или в качестве активного слоя фотовольтаических элементов. Для проведения исследований фотостабильности CIS/ZnS КТ и гибридных структур МНГ/CIS/ZnS КТ в данной работе была применена методика оценки скорости процессов фотоиндуцированного изменения состояния поверхности КТ, предложенную ранее нашей группой для исследования фотостабильности $\mathrm{CdSe} / \mathrm{ZnS}$ KT [23]. Данная методика заключается в сравнительном исследовании процессов фотоактивации/фотодеградации КТ на диэлектрической подложке и находящихся в составе гибридных структур с МНГ и использовании оценок эффективности взаимодействия КТ со вторым компонентом гибридной структуры. Предложенная методика позволяет оценить константу скорости фотодеградации каждой фракции КТ, если известна скорость переноса энергии/заряда между компонентами структуры.

Зависимости характерных времен и амплитуд каждой из трех компонент затухания люминесценции CIS/ZnS КТ, расположенных на диэлектрической подложке, от дозы облучения приведены на рис. 8 .

Данные, приведенные на рис. $8, a$ и 8, $b$, показывают, что времена и амплитуды всех компонент затухания люминесценции CIS/ZnS KT заметно меняются с увеличе- 
Таблица 1. Параметры аппроксимации кривых затухания люминесценции CIS/ZnS KT мультиэкспоненциальной функцией

\begin{tabular}{|c|c|c|c|c|c|c|c|c|c|}
\hline \multirow[t]{2}{*}{ Структура } & \multirow[t]{2}{*}{$\tau_{1}, \mathrm{~ns}$} & \multicolumn{2}{|c|}{$\mathrm{A}_{1}$} & \multirow[t]{2}{*}{$\tau_{2}, \mathrm{~ns}$} & \multicolumn{2}{|c|}{$\mathrm{A}_{2}$} & \multirow[t]{2}{*}{$\tau_{3}, \mathrm{~ns}$} & \multicolumn{2}{|c|}{$\mathrm{A}_{3}$} \\
\hline & & counts & $\%$ & & counts & $\%$ & & counts & $\%$ \\
\hline CIS/ZnS & $21 \pm 1$ & $754 \pm 16$ & 48.6 & $102 \pm 3$ & $646 \pm 14$ & 41.6 & $321 \pm 9$ & $150 \pm 10$ & 9.7 \\
\hline МНГ/CIS/ZnS & $6.2 \pm 0.5$ & $191 \pm 7$ & 82.9 & $43 \pm 5$ & $32 \pm 4$ & 13.7 & $208 \pm 24$ & $8 \pm 1$ & 3.4 \\
\hline
\end{tabular}

Примечание. *Экспериментальные кривые затухания люминесценции образцов аппроксимировались согласно формуле (1).
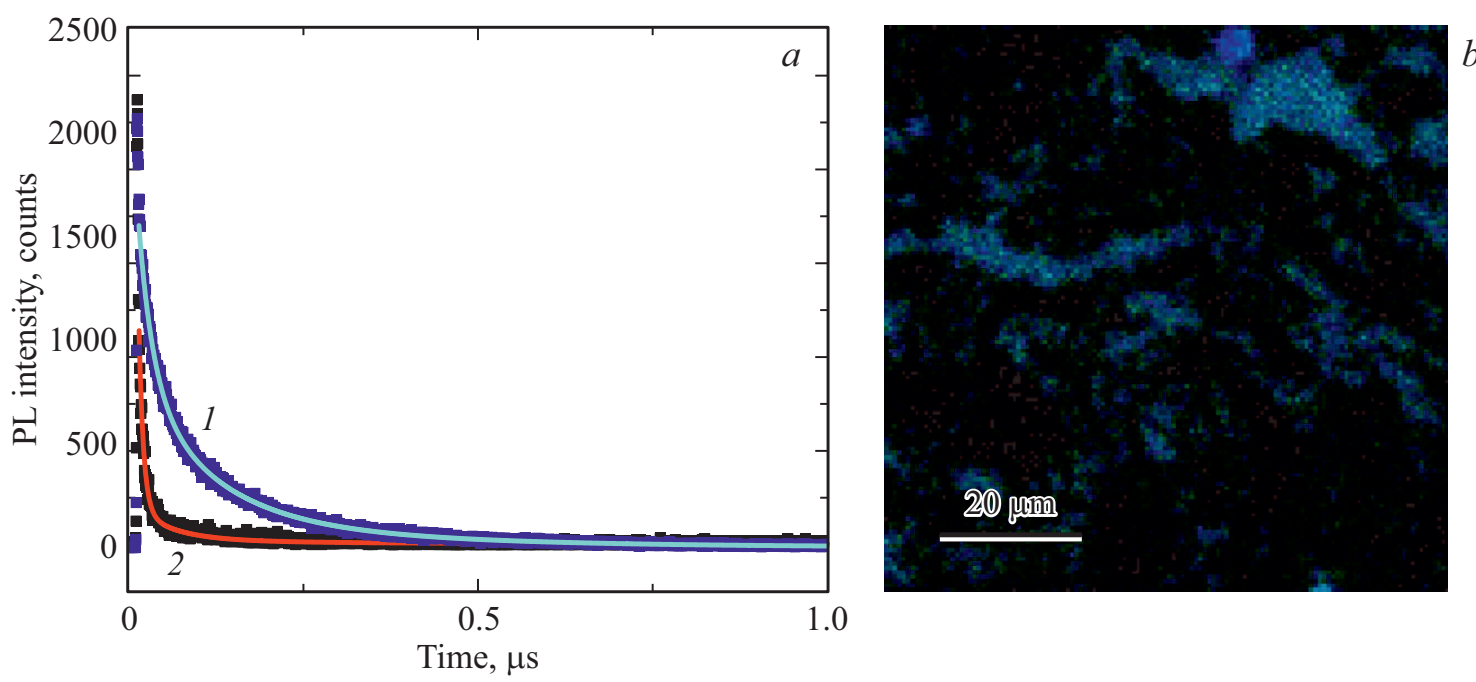

Time, $\mu$ s

Рис. 6. (a) Кривые затухания люминесценции $\mathrm{CIS} / \mathrm{ZnS}$ КТ на диэлектрической подложке (1) и в составе гибридных структур с МНГ (2). Сплошные линии - результат аппроксимации. (b) Люминесцентное изображение пленки с гибридными структурами MHГ/CIS/ZnS KT, где светлые области КТ на диэлектрической подложке, темные области - гибридные структуры MHГ/CIS/ZnS KT.

нием дозы облучения, указывая на фотоиндуцированное изменение состояния поверхности КТ.

На рис. 9 приведены характерные времена затухания люминесценции и амплитуды вклада фракций CIS/ZnS КТ, находящихся в составе гибридных структур с МНГ, в зависимости от дозы внешнего облучения. Данные, приведенные на рис. 9, $a$ и 9, $b$, показывают, что аналогично люминесценции монослоя КТ на диэлектрической подложке люминесценция CIS/ZnS KT в составе гибридных структур с МНГ также заметно меняется с увеличением дозы облучения.

Анализ параметров характерных времен затухания и амплитуд люминесценции для каждого излучательного перехода в КТ до и после фотооблучения позволил оценить эффективность тушения люминесценции, связанную с формированием новых каналов безызлучательной релаксации электронного возбуждения в КТ в результате фотодеструкции их поверхности:

$$
Q_{1}^{P D}=\left|\frac{A_{i} \tau_{i}}{A_{i 0} \tau_{i 0}}-1\right| \cdot 100 \%,
$$

где $A_{i}$ - концентрация КТ с характерным временем затухания люминесценции $\tau_{i}$, эквивалентная амплитуде $i$-го компонента затухания люминесценции КТ; индекс

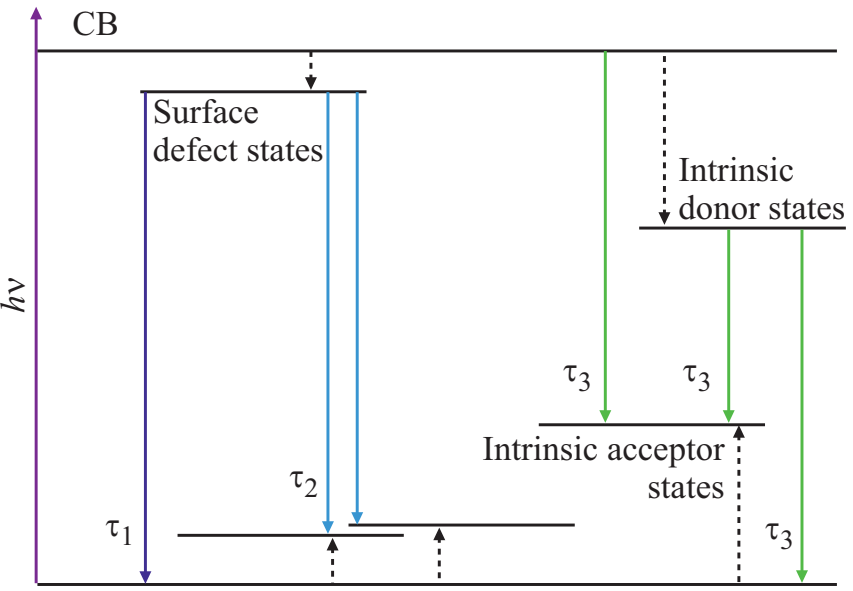

VB

Рис. 7. Принципиальная схема возможных излучательных переходов в CIS/ZnS KT: из зоны проводимости (CB) до поверхностных дефектов (излучательный переход с $\tau_{1}$ ); из зоны проводимости до локализованного внутризонного состояния (излучательный переход с $\tau_{2}$ ); рекомбинация из внутренних донорных состояний в собственные акцепторные состояния (излучательный переход с $\tau_{3}$ ). 
Таблица 2. Эффективность фотоиндуцированного тушения люминесценции CIS/ZnS KT

\begin{tabular}{c|c|c|c}
\hline $\begin{array}{c}\text { Эффективность } \\
\text { фотоиндуцированного } \\
\text { тушения люминесценции } \\
\text { КТ } Q_{i}^{P D *}, \%\end{array}$ & Компонента 1 $\left(\tau_{1}\right)$ & Компонента 2 $\left(\tau_{2}\right)$ & Компонента 3 $\left(\tau_{3}\right)$ \\
\hline На диэлектрической подложке & & & \\
В составе структур МНГ/КТ & $94.4 \pm 0.5$ & $93.2 \pm 0.5$ & $79.1 \pm 0.5$ \\
\end{tabular}

Примечание. * Рассчитана по формуле (2).

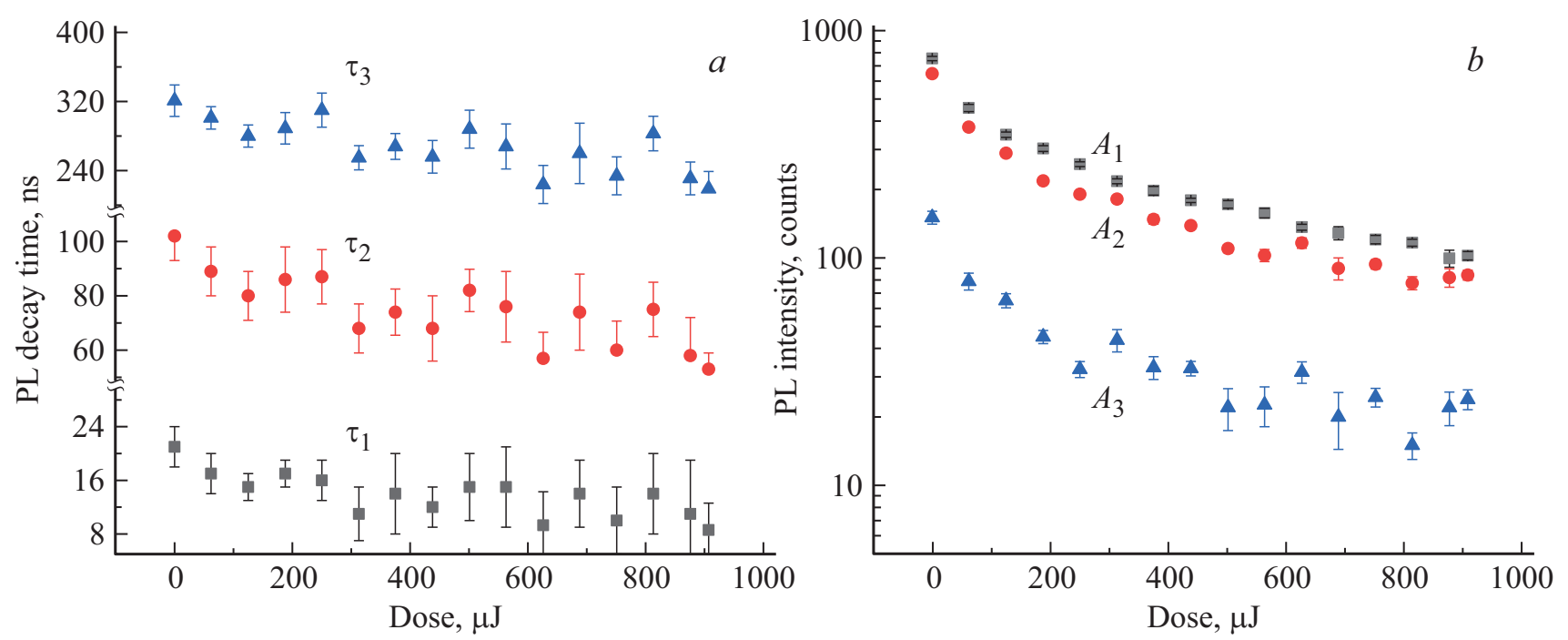

Рис. 8. Времена затухания люминесценции (a) и амплитуды интенсивности люминесценции $(b) \mathrm{CIS} / \mathrm{ZnS}$ KT, измеренные во время облучения КТ светом с длиной волны $409 \mathrm{~nm}$ и средней мощностью $1 \mu \mathrm{W}$ в пятне фокусировки диаметром $\sim 50 \mu \mathrm{m}$.
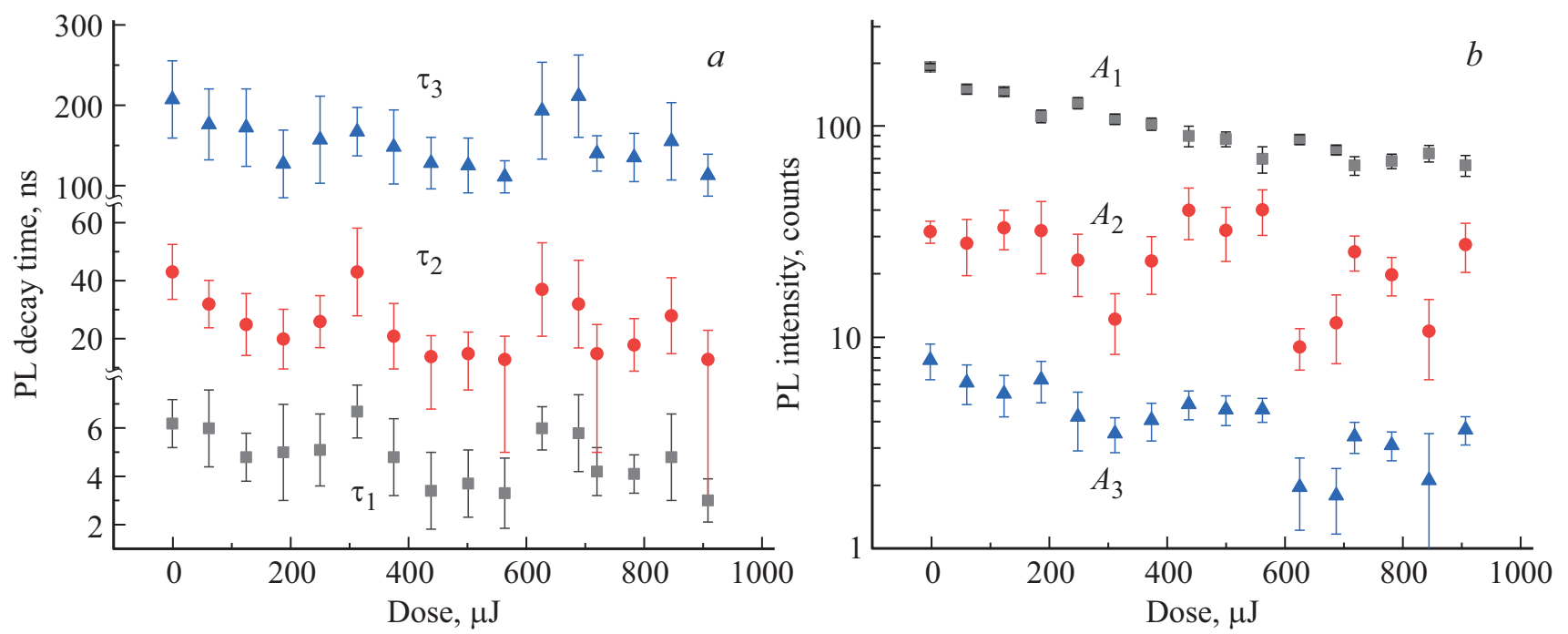

Рис. 9. Времена затухания люминесценции (a) и амплитуды интенсивности люминесценции $(b) \mathrm{CIS} / \mathrm{ZnS}$ KT в составе гибридных структур с МНГ, измеренные во время облучения КТ светом с длиной волны $409 \mathrm{~nm}$ и средней мощностью $1 \mu \mathrm{W}$ в пятне фокусировки диаметром $\sim 50 \mu \mathrm{m}$. 
„0“ относится к ансамблю КТ до взаимодействия с внешним облучением.

В табл. 2 приведены оценки эффективности фотоиндуцированного тушения люминесценции для трех излучательных переходов в КТ. Для всех CIS/ZnS КТ, расположенных на диэлектрической подложке, эффективность фотоиндуцированного тушения люминесценции превысила 90\%. При этом из табл. 2 видно, что при переходе от КТ на диэлектрической подложке к гибридным структурам с МНГ эффективность этого процесса уменьшается на $10-20 \%$.

Полученные данные показывают, что при переходе от CIS/ZnS КТ на диэлектрической подложке к гибридным структурам с МНГ наблюдается снижение эффективности фотодеструкции КТ. Это свидетельствует о том, что перенос энергии/заряда от КТ на МНГ конкурирует с фотодеструкцией. Однако стоит отметить, что эффективность канала переноса энергии/заряда в гибридной структуре MHГ/CIS/ZnS на порядок ниже, чем в гибридных структурах типа МНГ/CdSe/ZnS $[23,24]$. Так, в работе [23], ранее опубликованной нашей группой, была произведена оценка эффективности фотоиндуцированного изменения состояния поверхности $\mathrm{CdSe} / \mathrm{ZnS}$ KT, составившая $\sim 100 \%$ для CdSe/ZnS KT на диэлектрической подложке и $\sim 10 \%$ для $\mathrm{CdSe} / \mathrm{ZnS}$ KТ в составе гибридных структур с МНГ. Поскольку оба типа КТ имеют одинаковую полупроводниковую оболочку $\mathrm{ZnS}$ и именно она подвергается фотодеструкции, можно полагать, что на поверхности обеих типов КТ происходят одни и те же фотохимические процессы, приводящие к фотодеструкции поверхности КТ. Это позволяет оценить скорость взаимодействия CIS/ZnS KT с МНГ в составе структур, которая в данной системе составила $10^{6}-10^{7} \mathrm{~s}^{-1}$ в зависимости от рассматриваемого излучательного перехода CIS/ZnS KT.

\section{4. Выводы}

В работе исследованы люминесцентные свойства CIS/ZnS KT на диэлектрической подложке и в составе гибридных структур на основе МНГ. Показано, что CIS/ZnS KT обладают экспоненциальной зависимостью эффективности передачи энергии/заряда от количества монослоев графена, как и CdSe/ZnS KT. Анализ кинетики люминесценции CIS/ZnS KT, расположенных на диэлектрической подложке и в составе гибридных структур с МНГ, позволил выделить 3 основные компоненты, отвечающие за люминесценцию КТ и характеризующихся временами затухания порядка 20, 100 и $300 \mathrm{~ns}$. Продемонстрировано наличие эффективного канала переноса энергии/заряда в гибридной структуре. Анализ фотоиндуцированных процессов в КТ, расположенных на диэлектрической подложке и в составе гибридных структур с МНГ, позволил установить, что скорость взаимодействия КТ с МНГ в составе гибридных структур сопоставима со скоростью переноса энергии/заряда на дефектные поверхностные состояния на оболочки $\mathrm{ZnS}$, участвующие в ее фотодеструкции и составляет $10^{6}-10^{7} \mathrm{~s}^{-1}$.

\section{Финансирование работы}

Работа выполнена при поддержке Федеральной целевой программы по исследованиям и разработкам Министерства науки и высшего образования Российской Федерации, грант № 14.587.21.0047 (ID RFMEFI58718X0047).

\section{Конфликт интересов}

Авторы заявляют, что у них нет конфликта интересов.

\section{Список литературы}

[1] Wu P.-J., Yu J.-W., Chao H.-J., Chang J.-Y. // Chemistry of Materials. 2014. V. 6. N 11. P. 3485-3494.

[2] Pan Z.X., Mora-Sero I., Shen Q., Zhang H., Li Y., Zhao K., Wang J., Zhong X.H., Bisquert J. // J. American Chem. Soc. 2014. V. 136. N 25. P. 9203-9210.

[3] Chen CW., Wu D.Y., Chan Y.C., Lin C.C., Chung P.H., Hsiao M., Liu R.S. // J. Phys. Chem. C. 2015. V. 119. N 5. P. 2852-2860.

[4] Martynenko I.V., Kusic D., Weigert F., Stafford S., Donnelly F.C., Evstigneev R., Gromova Y., Baranov A.V., Kunte H.-J., Gun'ko Y.K., Resch-Genger U. // Anal. Chem. 2019. V. 91. P. 12661-12669.

[5] Dai X., Zhang Z., Jin Y., Niu Y., Cao H., Liang X., Chen L., Wang J., Peng $X$. // Nature. 2014. V. 515. N 525. P. 96-99.

[6] Akkerman Q.A., D’Innocenzo V., Accornero S., Scarpellini A., Petrozza A., Prato M., Manna L. // Chem. Soc. 2015. V. 37. N 32. P. $10276-10281$.

[7] Nam D.E., Song W.S., Yang H. // J. Materials Chem. 2011. V. 21. N 45. P. $18220-18226$.

[8] Kolny-Olesiak J., Weller H. // ACS Appl. Materials \& Interfaces. 2013. V. 5. N 23. P. 12221-12237.

[9] Chen C.W., Wu D.Y., Chan Y.C., Lin C.C., Chung P.H., Hsiao M., Liu R.S. // J. Phys. Chem. C. 2015. V. 119. N 5. P. 2852-2860.

[10] Castro S.L., Bailey S.G., Raffaelle R.P. // Chemistry of Materials. 2003. V. 15. P. 3142.

[11] Nakamura H., Kato W., Uehara M. // Chemistry of Materials. 2006. V. 18. P. 3330-3335.

[12] Chuang P.-H., Lin C.C., Liu R.-S. // ACS Applied Materials \& Interfaces. 2014. V. 6. N 17. P. 15379-15387.

[13] Song W.S., Yang H. // Chem. Mater. 2012. V. 24. № 10. P. $1961-1967$.

[14] Nguyen A.T., Gao F., Baucom D., Heyes C.D. // J. Phys. Chem. C. 2020. V. 124. N 19. P. 10744-10754.

[15] Wang Z., Zhang X., Xin W., Yao D., Liu Y., Zhang L., Liu W., Zhang $W$., Zheng $W$., Yang B., Zhang $H$. // Chemistry of Materials. 2018. V. 30. N 24. P. 8939-8947.

[16] Zasadzinski J.A., Viswanathan R., Madsen L., Garnaes J., Schwartz D.K. // Science. 1994. V. 263. N 5154. P. 1726.

[17] Justo Y., Moreels I., Lambert K., Hens Z. // Nanotechnology. 2010. V. 21. N 29. P. 295606. 
[18] Wang X., Liang Z., Xu X., Wang N., Fang J., Wang J., $X u$ G. // J. Alloys and Compounds. 2015. V. 640. P. 134-140.

[19] Kuzmenko A.B., van Heumen E., Carbone F., van der Marel D. // arXiv preprint arXiv:0712.0835.

[20] Chen Z., Berciaud S., Nuckolls C., Heinz T.F., Brus L.E. // ACS Nano. 2010. V. 4. N 5. P. 2964-2968.

[21] Goodfellow K.M., Chakraborty C., Sowers K., Waduge P., Wanunu M., Krauss T., Driscoll K., Vamivakas A.N. // Appl. Phys. Lett. 2016. V.108. N2. P.02110.

[22] Whitham P.J., Marchioro A., Knowles K.E., Kilburn T.B., Reid P.J., Gamelin D.R. // J. Phys. Chem. C. 2016. V. 120. N 30. P. 17136-17142.

[23] Reznik I., Zlatov A., Baranov M., Zakoldaev R., Veniaminov A., Moshkalev S., Orlova A. // Nanomaterials. 2020. V. 10. N 4. P. 714.

[24] Gromova Y., Alaferdov A., Rackauskas S., Ermakov V., Orlova A., Maslov V., Moshkalev S., Baranov A., Fedorov A. // J. Appl. Phys. 2015. V. 118. N 10. P. 104305. 